\title{
AFIDOS (HOMOPTERA:APHIDAE) DEL VALLE DE CAÑETE (LIMA - PERU)
}

\author{
CARMEN L. LEÓN \\ MENANDRO S.ORTIZ \\ Facultad de Ciencias Biológicas \\ universidad Ricardo Palma \\ Apartado 138,Lima - Peru
}

\section{RESUMEN}

\begin{abstract}
Se han identificado las siguientes especies procedentes del valle de Cañete : Aphis citricola, A.craccivora, A. fabae, A.gossypii,Brevicoryne brassicae, Lypaphis erysimi Macrosiphum euphorbiae, M. rosae, Myzus persicae, Rhopalosiphum maidis, R. Padi,toxoptera aurantii, T. citricidus y tuberolachnus salignus Todos los áfidos identificados representan especies de importancia económica, excepto el último.

PALABRAS CLAVE:Aphididae, Cañete, Lima,Perú
\end{abstract}

\section{SUMMARY}

Proceeding of cañete valley are identified the following species of aphids: Aphis citricola,A. craccivora, A. fabae, A. gossypii, Brevicoryne brassicae, Lypaphis erysimi, Macrosiphum euphorbiae, M. rosae, Myzus persicae, Rhopalosiphum maidis, R. padi, Toxoptera aurantii, T. citricidus y Tuberolachnus salignus. All of the are species of economic importance, except the last.

KEY WORDS: Aphididae, Cañete, Lima, Perú

\section{INTRODUCCION}

Sabiendo de la importancia que representan los áfidos, así como de la necesidad de conocer las especies que se presentan en diversas épocas y localidades del país, conjuntamente con sus hospederos, es que el presente trabajo contribuye a tales objetivos.

Diversas especies de áfidos representan un problema muy serio en plantas cultivadas de importancia agrícola, ornamental o de otra índole, debido a su comportamiento de plaga directa o indirecta.

En el primer caso, por extraer relativamente grandes volúmenes de savia por medio de sus piezas bucales y por eliminar parte de este alimento no digerido como melaza, sobre el cual desarrolla el hongo de la fumagina, impidiendo a la planta que desarrolle, sobre aquellas áreas ennegrecidas, la función fotosintética. Como plaga indirecta, se comporta transmitiendo una serie de virus fitopatógenos, que ocasionan diversos tipos de enfermedades a las plantas, causando como en el primer caso, un alto perjuicio económico.

\section{ANTECEDENTES}

Los primeros trabajos que citan a especies de áfidos del Perú son los de Wolcott (1928) y el de Towsend (1939), cuando tratan a especies de importancia del algodonero y caña de azúcar. Posteriormente, Wille $(1943,1952)$ en su primera y segunda edición de su obra sobre Entomología Agrícola del Perú incide en especies adicionales de pulgones, siempre desde un punto de vista económico.

Es a partir de los trabajos de Smith (1971a, b) que prácticamente se inician los trabajos taxonómicos sobre áfidos del Perú, siguiendo posteriormente aquellos de Ortiz $(1972,1973,1974)$ donde presenta inventarios y registros nuevos de especies de áfidos para el país y el de Ortiz et al . (1981) en donde tratan a especies de importancia en cebada. Se citan también los trabajos de Valencia et al . (1975) y de Rubin de Celis y Ortiz (1994), quienes, de la misma manera, contribuyeron al conocimiento de este importante grupo de insectos.

\section{MATERIALES Y METODOS}

Los ejemplares de áfidos provienen del valle de Cañete, localizado a $147 \mathrm{Km}$ al sur de Lima. De acuerdo ala ONERN (1976) el área estudiada pertenece a una formación ecológica denominada Desierto Desecado Subtropical. Para el presente trabajo, debido a la presencia de especies de plantas hospederas,se dividió el área de estudios en dos zonas: alta y baja,señalando que otras especies de plantas eran comunes para las dos zonas. La zona baja corresponde a Imperial, Quilmaná y Nuevo Imperial y a la zona alta comprende a San Luis y San vicente. 
La coleción se efectuó sobre plantas de importancia económica y sobre malezas,desde el 02 de julio hasta 29 de agosto de 1992. Todo el material colectado queda depositado en el Museo de Historia Natural de la Universidad Ricardo Palma.

\section{RESULTADOS}

\section{Aphis citricola Van Der Goot}

Colecta sobre brotes nuevos de mandarina y manzano. Cermeli (1967) cuando se refiere a Aphis citricola le atribuye preferencia por árboles, en donde produce deformación de los brotes y atraso en el crecimiento. Esta especie ha sido confundida con Aphis pomi y segun Cermeli (1967),no hay forma de diferenciarla por falta de formas sexuales. Pero según Smith et al. (1963) Aphis citricola tiene tubérculos abdominales sobre los segmentos abdominales I y VII, mientras que Aphis pomi tiene sobre el VII. Asimismo, , Blackman y Eastop (1985), las diferencian por que Aphis citricola tiene el último segmento del rostrum más corto que el de Aphis pomi.

Aphis citricola tiene gran importancia en nuestro medio por ser considerado como un vector del virus de la tristeza en citricos.

Martín (1969), lo señala como vector de la enfermedad»deformación foliar» de Carica papaya .

Material observado:

Citrus sp. «Mandarina» (Rutaceae), Quilmaná (02.VII.92):6 alados, 37 ápteros y 50 ninfas ; San Vicente,(01-VIII-92):3alados, 12 ápteros y 76 ninfas.

Malus sp. «Manzano» (Rosaceae),Nuevo Imperial (15.VIII.92) 17 alados, 26 ápteros y 150 ninfas;San Vicente, Zona baja (07.VIII.92): 11 alados, 2 ápteros y 240 ninfas.

\section{Aphis craccivora Koch}

Colectada en el envés de hojas de pallar. Esta observación concuerda con lo mencionado por Carmeli (1967), en relación con su preferencia por las leguminosas. En otros países es plaga sobre Vicia fama, Phaseolus vulgaris y trifolium repens, aunque también es factible encontrarla infestando otros hospederos. En Venezuela, Aphis craccivora presenta importancia económica; Martin (1969), la cita como vector del virus de la «deformación foliar de Carica papaya. En Ica ha sido registrada sobre brotes tiernos de cerezo (Prunus aviun)por Valencia y Cárdenas (1973),con lo cual se confirma sus hábitos polífagos.Es cosmopolita.
Esta especie se distingue principalmente por el cuerpo negro brillante,especialmente de las formas ápteras;las porciones distales delas patas son blanquecinas, pocas setas sobre la cauda y pocos sensorios secundarios sobre el segmento antenal III de las formas vivíparas aladas.

\section{Cañete}

Esta especie constituye nuevo registro para el valle de Material observado:

Phaseolus lunatus «Pallar» (Leguminosae),Nuevo imperial Zona Alta (02.VII.92): 3 alados, 34 ápteros y 188 ninfas.

\section{Aphis fabae Scopoli}

Especie cosmopolita,con un amplio rango de hospederos,presentándose algurias veces como plaga de cítricos.En el caso particular de Cañete es la especie más difundida,encontrándose en diferentes cultivos en toda las zonas; siendo mas frecuente en la zona baja. Estas observaciones concuerdan con lo señalado por Blackman y Estop (1985); quienes indican que es altamente polífaga y de gran importancia agricola por ser transmisor de más de 30 virus en diversos cultivos como tomate,papa y otros.

Las características más saltantes de esta especie son el color verde olivo oscuro a negro,cauda con muchas setas y el número de sensorios secundarios sobre los segmentos III,IV Y V de las formas aladas.

Esta especie constituye nuevo registro para el valle de Cañete

Material observado:

Chenopodium murale «Hierba de gallinazo» (Chenopodiaceae), Quilmaná, zona alta (02.II.92): 5 alados, 7 áteros y 95 ninfas.

Lens sculentum «Lenteja» (Leguminosae),Nuevo Imperial, zona alta (16.VIII.92): 4 alados, 2 ápteros y 49 ninfas.

Lycopersicum sculentum «Tomate» (solanaceae), San Vicente,zona baja (01.VIII.92): 13 alados y 7 ninfas.

Solanum tuberosum "papa» (Solanaceae), San Vicente, zona baja (07.VIII.92): 2 alados, 1 áptero y 30 ninfas.

Solanum nigrum «Hierba Mora» (Solanaceae),San Vicente,zona baja (26.VIII.92): 3 alados, 33 ápteros y 100 ninfas.

Datura stramonium «Chamico» (Solanaceae), San vicente zona baja (26.VIII.92): 48 alados 29 ápteros y 120 ninfas.

Rumex crispus «Lengua de vaca» (Polygonaceae),San Vicente,zona baja (29.VIII.92): 2 alados, 36 ápteros y 180 ninfas. 


\section{Aphis gossypii Glover}

Cosmopolita e importante en la agricultura como especie plaga en el algodonero y con un amplio rango de plantas hospederas. Townsed (1939), la cita atacando frecuentemente los botones terminales y las hojas del algodonero. Sus colonias son por lo general abundantes.

En Venezuela según Çermeli (1967) está presente durante todo el año, hospedándose sobre hortalizas en verano y en invierno sobre el algodonero.

También es importante vector de enfermedades virósicas en este sentido, Martin (4969), en Venezuela, corrobora a Aphis gossypii (Glober) como vector de la enfermedad «deformación foliar» de Carica papaya.

En nuestro medio y principalmente en Cañete,esta especie ha sido considerada, durante años,una de las plagas principales del algodonero, atribuyéndosele las manchas de la fibra del algodón ocasionada por la melaza y consecuentemente, el mal desarrollo de la planta. Efectivamente, fue colectada sobre algodonero y en otros cultivos. Asimismo, en zapallo fue colectada en las 2 zonas; en en la zona baja se le encontró asociada con Myzus persicae, especie altamente polífaga. Stroyan (1961), la encontró asociada con Taxoptera aurantii y Aphis craccivora.

En Cañete, durante el año 1985, Aphis gossipii causó gravísimos daños, aplicando los agricultores productos agroquímicos sin tener buenos resultados. Se notó que la población de Aphis gossypii de color negro fue la más resistente ya que, hasta entonces, los que habían estado afectando eran controlables y de color verde.

Material observado:

Cucurbita maxima «Zapallo» (Cucurbitaceae), Quilmaná, zona alta (03.VIII.92): 7 alados, 2 ápteros y 57 ninfas.

Solanum muricatum «Pepino» (Solanaceae), Quilmaná, zona alta (03.VII.92): 7 alados, 43 ápteros y 110 ninfas.

Solanum tuberosum «Papa» (Solanaceae) Nuevo Imperial, zona alta (02.VII.92): Quilmaná, zona alta (03.VII.92): 3 alados, 22ápteros y 143 ninfas.

Gossypium barbadense «Algodon» (Malvaceae) Nuevo Imperial, zona alta (02.VII.92); Imperial, zona alta (22.VII.92): 3 alados, 53 ápteros y 57 ninfas; San Vicente, zona baja (01.VIII.92): 3 alados, 10 ápteros y 5 ninfas.

Lycopersicum sculentum «Tomate» (Solanaceae), Quilmaná, zona alta (03.VII.92): 15 alados.

Persea americana «Palta» (Lauraceae), Nuevo Imperial, zona alta (16.VIII.92): 29 alados , 100 ápteros y 90 ninfas.
Phaseolus vulgaris «Frijol» (Leguminosae) Nueva Imperial, zona alta (18.VIII.92): 103 alados.

\section{Brevicoryne brassicae (Linnaeus).}

Cosmopolita, plaga importante sobre crucíferas; colectada en la zona baja sobre coliflor. Reportada por Wille (1943) y mencionada por Valencia y Cárdenas (1973), sobre nabo y col, notando que al parecer la elevada humedad relativa, es un factor que contribuye a la existencia de grandes colonias entre las hojas de col.

Del mismo modo, Cermeli (1967), en Venezuela cita esta especie en zonas altas detectadas en cultivos de crucíferas. Cabe incidir que la humedad relativa es elevada en zonas altas de Venezuela.

Por lo tanto, se deduce que su presencia en la zona baja de Cañete se debe a la existencia de humedad relativa elevada.

Sus principales características son el color verde grisáceo recubierto por una pulverulencia cerosa. Cornículos cortos y algo hinchados, cauda corta y de forma triangular. Presenta un comportamiento oligófago y tanto por su frecuencia como por su abundancia se traduce en una de las especies de mayor importancia económica. Cañete.

Esta especie constituye nuevo registro para el valle de

Material observado:

Brassica olareacea «Coliflor» (Cruciferacea); San Vicente, zona alta (01.VIII.92): 1 alado, 16 ápteros, y 190 ninfas.

\section{Lipaphis erysimi (Kaltenbach)}

Colectada sobre nabo en la zona baja de Cañete; zona de mayor porcentaje de humedad. También presenta preferencia por crucíferas cultivadas.

Citado como Hyadaphis erysimi por Cermeli (1967) y Kono \& Papp (1977). Smith (1971a) la cita comoLipaphis psuedobrassicae. Blackman \& Eastop (1985) mencionan que esta especie en condiciones humedas es frecuente encontrarla densamente cubierta por una pulverulencia cerosa. Posee menor pulverulencia cerosa que Brevicoryne brassicae. De este modo lo resalta Cermeli (1967).

Sus principales características estan en los numerosos sensorios sobre el segmento antenal III y IV de las formas vivíparas aladas como la cauda corta con cinco setas y los cornículos cortos y algo inflados.

Esta especie constituye un nuevo registro para el valle de Cañete 
Material observado:

Brassica napus «nabo" (Cruciferaceae); San Vicente zona baja (26.VIII.92): 6 ápteros y 144 ninfas.

\section{Macrosiphum euphorbiae (Thomas)}

Citada anteriormente en nuestra literatura como Macrosiphum solanipholii. Colectada en la zona alta en colonias mixtas, con Myzus persicae, sobre camote y en la zona baja se notó su preferencia por solanaceas. Wille (1943) la menciona como especie de hábitos muy variados. En Venezuela, Cermeli (1967) citó esta especie proveniente de Solanáceas.

Blackman \& Eastop (1985) hace referencia de esta especie como altamente polífaga, pudiéndose hospedar sobre 200 especies de plantas de más de 20 diferentes familias, entre las que destacan las solanáceas. Es cosmopolita y de gran importancia en la agricultura; vector de más de 40 virus no persistentes y 5 virus persistentes incluyendo la enfermedad del enrrollamiento de la hoja de la papa en menor proporción que Myzus persicae.

Las principales características de Macrosiphum euphorbiae son los cornículos oscuros y reticulados en su parte distal; cauda alargada y en forma de espátula y el número de setas que presenta, así como el número de sensorios sobre el segmento antenal III.

\section{Material observado:}

Ipomoea batatae «Camote» (Convolvulaceae); Imperial, zona alta (180.VIII.92): 3 alados, 20 apteros y 150 ninfas en brotes; conjuntamente con Myzus persicae.

Datura stramonium "Chamico» (Solanaceae); San Vicente, zona baja (21.VIII.92): 1 áptero, conjuntamente con Aphis fabae.

Nycandra physaloides «Capulí cimarrón» (Solanaceae); Zona Baja (29.VIII.92): 5 alados, 11 ápteros y 180 ninfas.

\section{Macrosiphum rosae (Linnaeus)}

Conocida comunmente como el áfido del rosal. Se colectó en la zona alta sobre tallos tiernos de rosa. En Venezuela Cermeli (1967) la cita como una de las especies más difundidas en todo el país. Rubín de Celis y Ortiz (1994) la reportaron también sobre rosa; pero que por sus altas poblaciones se presentó sobre otros hospederos, siendo por ello la especie más difundida en Canta.

Entre las principales características de esta especie figuran la coloración oscura de sus apéndices, la cauda pálida, la longitud y forma de los cornículos, el número de sensorios sobre el segmento antenal III, en mayor número que los de Macrosiphum euphorbiae.

\section{Esta especie constituye nuevo registro para el Valle de} Cañete.

Material observado:

Rosa sp. «Rosa» (Rosaceae); Nuevo Imperial, zona alta (16.VIII.92): 2 alados, 10 ápteros y 150 ninfas.

\section{Myzus persicae (Sulzer)}

Conocida comunmente como «áfido verde del melocotonero" es sin embargo altamente polífaga. Es la segunda especie más difundida en el Valle de Cañete tanto en zona alta como baja. De gran importancia agrícola, la mayoría de las veces compartiendo el hospedero con otra especie. Se le halla en hojas inferiores cercanas al suelo. Raman (1985), la considera como el principal vector de virus de papa, tanto persistente como no persistentes. Transmite el PLRV (virus del enrollamiento de la hoja de la papa), el cual es también el más importante. En términos generales transmite casi 50 virus distintos. Primo (1968) menciona para Chile que Myzus persicae es el principal vector de los virus de la papa.

Entre las principales características de Myzus persicae están el color verde claro, la placa oscura sobre el dorso del abdomen, los tubérculos antenales bien desarrollados, el número de sensorios secundarios sobre el segmento antenal III en las formas aladas y cornículos ligeramente hinchados.

Material observado:

Solanum tuberosum «Papa» (Solanaceae); Quilmaná, zona alta (02.II.92): 3 alados, 22 ápteros y 110 ninfas, en colonia mixta con Aphis gossypii; San Vicente, zona baja (01.VIII.92): 2 alados, 1 áptero y 30 ninfas, con Aphis fabae.

Capsicum annum «Ají» (Solanaceae); Imperial, zona alta (18.VIII.92): 1 alado, 39 ápteros y 73 ninfas.

Rosa sp. «Rosa» (Rosaceae); Nuevo Imperial, zona alta (16.VIII.92): 13 alados, 5 ápteros y 120 ninfas, en colonia mixta con Macrosiphum rosae.

Lens sculentum «Lenteja» (Leguminosae); Nuevo Imperial, zona alta (16.VIII.92): 4 alados, 2 ápteros y 49 ninfas.

Ipomoea batatae «Camote» (Convolvulaceae); Imperial, zona alta (18.VIII.92): 11 ápteros y 100 ninfas; San Luis, zona baja (18.VII.92): 2 alados, 5 ápteros y 150 ninfas. 
Lycopersicum sculentum «Tomate» (Solanaceae); San Vicente, zona baja (01.VIII.92): 4 alados, 2 ápteros y 7 ninfas.

Cucurbita maxima «Zapallo» (Cucurbitaceae); San Vicente, zona baja (01.VIII.92): 2 ápteros y 3 ninfas.

Brassica napus «Nabo» (Cruciferae); San Luis, zona alta (25.VIII.92): 4 ápteros y 44 ninfas.

\section{Rhopalosiphum maidis (Fitch)}

Colectada tanto en zona alta como en zonas baja del valle de Cañete, encontrándosele protegida en las hojas nuevas de las gramíneas. Los especimenes son por lo general de color verde olivo. En la zona baja se le encontró compartiendo el habitat con Rhopalosiphum padi sobre maíz.

Wille (1952) menciona a Rhopalosiphum maidis ocasionando daños sobre sembríos de trigo. Ortiz (1972) la cita como un áfido de gramíneas en su inventario de áfidos de la Costa Central. Del mismo modo, Valencia y Cárdenas (1973) citaron a Rhopalosiphum maidis y Rhopalosiphum padi como especies que se hallan sobre gramíneas cultivadas y silvestres. Se diferencia por la longitud del unguis del segmento antenal VI, más corto en Rhopalosiphum maidis. Importante vector de virosis persistente (Blackman \& Eastop, 1985).

Caracterizada por la forma y número de setas sobre la cauda, unguis corto y además en la forma alada pornúmero de sensorios sobre los segmentos antenales III, IV y V.

Material observado:

Zea mays «maíz» (Gramineae); Nuevo Imperial, zona alta (02.VII.92): 1 alado, 79. ápteros y 120 ninfas; Imperial, zona alta (22.VII.92): 1 alado, 3 áptero y 148 ninfas; San Vicente, zona baja (01.VIII.92): 1 alado, 14 ápteros y 67 ninfas.

Sorghum vulgaris "sorgo" (Gramineae); San Vicente, zona baja (25. VII, 92): 7 alados, 16 ápteros y 168 ninfas.

Sorghum hapelense "grama china" (Gramineae); San Vicente, zona baja (15,VIII, 92): 4 alados, 39 ápteros y 106 ninfas.

\section{Rhopalosiphum padi (Linnaeus)}

Citado por Wille (1952) como Rhopalosiphum prunipholiae. Colectada sobre maíz en las zonas alta y baja del valle de Cañete, encontrándose con mayor incidencia en la zona baja.

Valencia y Cárdenas (1973Z) en Ica, la citan sobre maíz. Según Smith et al. (1963), citado por Kolbe (1969), se presenta sobre trigo como especie de mayor importancia en Nueva Zelandia, transmitiendo el virus del enanismo amarillo de la cebada (BYDV), causando pérdidas en el orden del 25 por ciento.

Rhopolosiphum padi se caracteriza por la forma de la cauda y número de setas sobre ella, la longitud del unguis del segmento antenal VI y número de sensorios secundarios sobre los segmentos antenales III, IV y V.

\section{Material observado}

Zea mays "maíz" (Gramineae); Nuevo Imperial, zona alta (14, VIII, 92): 8 alados, 3 ápteros y 134 ninfas; San Vicente, zona baja (01.VIII. 92): 2 alados, 14 ápteros y 67 ninfas.

\section{Toxoptera aurantii (Boyer de Fonscolombe)}

Especie conocida como el pulgón negro de los cítricos. Fue colectada sobre brotes de mandarina en la zona baja de Cañete, en colonias mixtas con Aphis citricola y Toxoptera citricidus. No ha sido colectada, durante el presente estudio, en la zona alta.

Ortiz (1980) citó a esta especie como una principal plaga de cítricos, atacando también a hojas y brotes de cafeto, cacaotero, té y ficus. Fue reportada en aquella ocasió proveniente de Tingo María.

Cermeli (1967) consideró que se diferencia de otras especies por la reticulación dentada presente en el abdomen. La misma concepción presentan Smith et al. (1963); mientras que Kono y Papp (1977) consideran que el mecanismo estriadas sobre el abdomen seguido de los cornículos, es característica del género. Se comprobó este asunto al apreciar las mismas estrías en Toxoptera citricidus.

Se caracteriza por el cuerpo de color negro brillante, por tener una sola bifurcación de la media en las alas anteriores, así como por el área fuertemente estriada sobre la superficie del abdomen seguidamente de los cornículos.

Material observado:

Citrus sp. «mandarina» (Rutaceae); San Vicente, zona baja (01.VII.92): 4 alados, 87 ápteros y 216 ninfas; en colonias mixtas con Toxoptera citricidus y Aphis citricola.

\section{Toxoptera citricidus (Kirkaldy)}

Se trata del áfido marrón de los cítricos, colectada sólo en la denominada zona baja, compartiendo hábitats con Toxoptera aurantii y Aphis citricola, sobre brotes de mandarina. Blackman \& Eastop (1985) consideran para 
esta especie un rango de hospederos más estrecho que para Toxoptera aurantii. Es considerada comola principal vectora del virus de la tristeza. Sus características más saltantes son la cauda con numerosas setas, cuerpo negro brillante con apéndices más claros, pudiéndose observar también reticulaciones ya mencionadas para Toxoptera aurantii.

Material observado:

Citrus sp. «mandarina» (Rutaceae); San Vicente, zona baja (01.VIII.92): 8 alados, 78 ápteros y 200 ninfas; conformando colonias mixtas con Toxoptera aurantii y Aphis citricola.

\section{Tuberolachnus salignus (Gmelin).}

Es la especie colectada de mayor tamaño, comunmente llamado áfido del sauce. Observada precisamente en sauce tanto en zona alto alta como en zona baja del Valle de Cañete; siendo en la zona baja en donde se encontró formas aladas, ápteras y ninfas; mientras en zona alta se observő solo formas ápteras.

Valencia y Cárdenas (1973), lo citan como el pulgón más grande colectado en Ica, a la cual no se le han registrado enemigos naturales.

Valencia et al. (1975) mencionan a esta especie ampliamente distribuída en el Perú, sobre el sauce, aunque también ha sido colectada sobre peras y membrillo.

Es de color grisáceo con un tubérculo negro bien marcado en el dorso del abdomen. Viven en ramas y troncos del sauce, siendo colectadas solamente en zonas de climas templados.

Esta especie constituye nuevo registro para Cañete.

Material observado:

Salix humboldtiana «sauce» Imperial, zona alta (02.VII.92): 7 ápteras y 2 ninfas; San Vicente, zona baja (26.09.92): 6 alados, 7 ápteros y 45 ninfas.

\section{REFERENCIAS BIBLIOGRAFICAS.}

BLACKMAN, R.L. and V.F. EASTOP.1985. Aphids on the World's Crops: An identification Guide. John Willey \& Sons. England, 466 pp.

CERMELI, M. 1967. Los Afidos de importancia agrícola en Venezuela y algunas observaciones sobre ellos. VII Reunión Latino Americana de Fitotecnia ALAF 26 pp.

HILLE RIS LAMBERS, D. 1950. On mounting aphids and other soft skinned insects. Ent. Berichten, Amst., 13: 55 - 58 .
KOLBE, W. 1969. Investigación sobre la aparición de diversas especies de pulgones como causa de mermas de rendimiento y calidad en cerealicultura. Pflanzenschutz Nachrichten. Bayer, 22 : 187.

KONO, T. and CH. PAPP. 1977. Handbook of agriculture pest aphis, thrips, mites, snails on slugs. Departament of Food and Agriculture Division of Plant Industry. 205 pp.

MARIN, A. J. 1969. Insectos relacionados con la lechosa (Carica papaya L.), en Venezuela. Rev. Agro. Trop. 19 : $251-67$.

ONERN. 1976. Mapa ecológico guía explicativa Lima Perú; 350 pp.

ORTIZ, M.S.1972. notas sobre algunas especies de áfidos del Perú. Resúmenes, XV Conv. Nac. Ent., Ica, Perú, pp. 87.

ORTIZ, M.S.1973. Rhopalosiphoninus latysiphon (Davison), un áfido de sifones peculiares. Rev. Per. Ent. 16: 125-126.

ORTIZ, M.S. 1974. Hallazgo de un macho de Myzus persicae (Sulzer). Rev. Per. Ent. 17: 127 - 128.

ORTIZ, M.S. 1980. Aphididae (Homoptera) procedentes de Ceja de Selva, Tingo María (Huánuco - Perú) . Rev. Per. Ent. 28: 119-120.

ORTIZ, M.S. A. RODRIGUEZ Y J. SARMIENTO. 1981. Los Afidos (Homoptera: Aphididae) de la cebada (Hordeum vulgare L.) en la Sierra y Costa Central del Perú. Rev. Per. Ent. 24: 133-136.

PRIMO, A. 1968. Los áfidos vectores del virus y su relación con la certificación de la semilla de papa en la zona Central de Chile. Rev. Fitotec. Latinoam. 5: 67-79.

RAMAN, K.V. 1985. Estudio de poblaciones de áfidos. Centro Internacional dela Papa (CIP). Serie IV-2, 12 pp.

RUBINDECELIS, V.E. y M.S. ORTIZ. 1994. Aphididae (Insecta: Homoptera) procedentes de Canta (Lima-Perú) Biotempo 1: $39-42$.

SMITH, C. L. MARTORELL y M. PEREZ.1963. Aphididae of Puerto Rico. Agricultural Experiment Station, Rio Piedras, Puerto Rico.Tech. Paper 37: 1 -121.

SMITH, C.F. 1971a. Survey of aphids on potatoes and beans in Peru with notes on aphis on the other plants. Firts Report, North Carolina State University, 11 pp.

SMITH, C.F. 1971b. Survey of aphids on potatoes in Peru with notes on Aphis on the other plants. Second Report, North Carolina State University, 31 pp. 
STROYAN, H. 1961 Identification of Aphis living on Citrus. FAO. Plant Protection Bulletin 9: 45-65.

TOWNSEND, C.H.T. 1939. Insectos que atacan al algodonero y caña de azúcar en el Perú. Estación Experimental Agrícola, La Molina, 40 pp.

VALENCIA, L. ; GUERRA, C y GUTARRA, F. 1975. Los áfidos (Homoptera: Aphididae) del valle del Mantaro; plantas hospederas y enemigos naturales. Rev. Per. Ent. 8: 90 -97.
VALENCIA, L. Y N. CARDENAS.1973.Los áfidos (Homoptera:Aphididae) del Valle de Ica, sus plantas hospederas y enemigos naturales. Rev. Per. Ent. 16: 6-14.

WILLE, J.E. 1943. Entomología Agrícola del Perú. Ministerio de Agricultura. Primera Edición 543 pp.

WILLE, J.E. 1952. Entomología Agrícola del Perú. Ministerio de Agricultura. Segunda Edición. 543 pp.

WOLCOTT, G.E. 1928. Los áfidos que afectan a la Industria Azucarera del Perú. Estación Experimental Agrícola la Molina, Lima - Perú, Cir. 12 : 1 -11. 